\title{
Facing exclusion and smiling through the pain: positive emotion expression during interpersonal ostracism
}

This article was published in the following Dove Press journal: Psychology Research and Behavior Management

\author{
Elena Svetieva' \\ Lisa Zadro ${ }^{2}$ \\ Daejoong Kim ${ }^{3}$ \\ Carolyn M Hurley ${ }^{4}$ \\ Rani Goodacre ${ }^{2}$ \\ 'Department of Communication, \\ University of Colorado, Colorado \\ Springs, CO, USA; ${ }^{2}$ School of Psychology, \\ University of Sydney, Sydney, NSW, \\ Australia; ${ }^{3}$ Department of Media \& \\ Communication, Dong-A University, \\ Busan, South Korea; ${ }^{4}$ Department of \\ Communication Studies and Theatre, \\ Northern Virginia Community College, \\ Sterling, VA, USA
}

Background: The present research compares smiling and emotion expression generally to other indicators of negative intra- and interpersonal reactions to ostracism, and in particular negative reactions towards the ostracizers.

Methods: A total of $\mathrm{N}=143$ participants ( $\mathrm{n}=55$ in Experiment 1 and $\mathrm{n}=88$ in Experiment 2) were ostracized from a web-conference by two other individuals. Facial expressions of participants during the exclusion period were coded using EMFACS and compared to selfreported reactions to ostracism and the sources of the ostracism.

Results: Ostracized individuals showed significant levels of both Duchenne (genuine) and non-Duchenne (social) smiling, despite finding ostracism highly aversive, reporting more negative attitudes towards the ostracizing confederates, and (in Experiment 2) higher levels of negative affect. Experiment 2 showed evidence of a self-regulation and display management function of smiling during ostracism in that participants who exhibited more Duchenne smiling during their exclusion also reported higher levels of positive emotion after the ostracism, and were also rated by a group of judges as experiencing more amusement at their exclusion.

Conclusion: The web conferencing paradigm used in this study provides an ecologically valid method to study the management of expressive behavior during aversive interpersonal experiences, adding to the existing evidence of facial display management during other types of distressing experience.

Keywords: ostracism, facial expressions, self-regulation, emotion, display rules

\section{Introduction}

Multiple models of emotion highlight the importance of facial expression as an integral component of emotion experience whose function is to communicate an individual's reactions to the situation and his/her behavioral intent. ${ }^{1,2}$ While facial expressions of emotion can provide a dynamic and unobtrusive indicator of affective change, ${ }^{3}$ they are also sensitive to the social and cultural context in which they occur. Concerns for self-presentation moderate much of what and how we communicate, ${ }^{4}$ and the same is true of affect displays. In a number of situations, individuals are suppressing negative emotion that they feel or expressing positive emotion they do not.

Display rules refer to our implicit understanding that we need to manage and conceal emotion in certain situations. ${ }^{5}$ The smile, for example, is a socially pleasant display that is often recruited in situations where individuals are not necessarily
Correspondence: Daejoong Kim

Department of Media \& Communication,

Dong-A University, 225 Gudeok-ro, Seo-gu,

Busan 49236, South Korea

$\mathrm{Tel}+821085978624$

Email daejoong@gmail.com 
feeling positive affect, such as smiling at an unfunny joke or smiling during embarrassment. ${ }^{6}$ Smiling during distress is often linked to the culturally mandated need to manage expressions in front of other people, ${ }^{7}$ but evidence suggests that facial expressions of positive emotion may even serve a spontaneous self-regulatory function, where smiling can serve as an intrapersonal coping mechanism. ${ }^{8}$

Smiling during distressing experiences can boost the levels of positive affect felt after the experience, and thus lessen subjective distress, ${ }^{6,9}$ and can also decrease objective stress markers such as heart rate. ${ }^{10}$ Additionally, some studies have established that not all smiling during distress is equivalent, but that Duchenne smiling, the type of smiling that is a true indicator of enjoyment (involving both the zygomatic major and the orbicularis oculi), is particularly important to consider. ${ }^{8,11}$ Duchenne smiling is also distinguishable from smiles that are displayed during embarrassment or nervousness. ${ }^{12}$ Although some have questioned the predictive utility of Duchenne smiles as indicators of enjoyment, ${ }^{13}$ Duchenne smiles are thought to have distinct behavioral markers, neural correlates and social perception outcomes. ${ }^{14,15}$

The majority of studies on this effect have used experimental paradigms in which emotion states are induced with media, ${ }^{8,9}$ or other distressing autobiographical monologues (eg, postbereavement). The present study seeks to expand on this research by examining smiling during an experimentally controlled, negative interpersonal experience of ostracism. Ostracism is the specific experience of being excluded or ignored by another person or group of people, and is in general an experience that individuals find to be highly aversive. ${ }^{16}$

Humans are social animals that experience an adaptive and fundamental need to belong. ${ }^{17}$ Experiences of social rejection and exclusion threaten this need, decreasing an individual's sense of belonging, control, self-esteem, and meaningful existence. ${ }^{18}$ Negative affective reactions play a large role in this process - an immediate experience of negative arousal signals to the individual that he or she is being rejected, ${ }^{19,20}$ and the more elaborate emotional reactions to being ostracized (typically sadness, anger, and hurt feelings) act as moderators and motivators for subsequent behavior. $^{21,22}$ Behavioral outcomes can be antisocial behavior but also reparative in nature. ${ }^{23}$

Despite ample evidence of negative self-reported affective reactions to ostracism, surprisingly little is known about the nature and function of emotion expression in ostracized individuals, especially in a social/interpersonal setting. Real world interviews with targets of ostracism point to individuals' concerted efforts to manage and control behavior during these periods and abstain from showing distress. ${ }^{24}$ However, there is currently no experimental evidence to support this observation. The few studies that have experimentally examined facial expressions in ostracism have utilized computer-simulations of ostracism that only nominally represent a social situation, have been limited to clinical comparisons of individuals with borderline personality disorders and healthy controls, ${ }^{25}$ and have measured nonspecific negative affect in targeted facial regions. ${ }^{26}$ For example, when participants were excluded from a decision-making task, they displayed fewer expressions of joy, and more of sadness, suggesting that the experience of exclusion does modulate facial behavior just as it affects internal affective reactions. ${ }^{27}$

\section{Overview of the research}

This research utilizes a paradigm that enables facial expressions of emotion to be measured during an ecologically valid, face-to-face interpersonal experience of ostracism. In contrast to previous studies, ${ }^{27}$ individuals experience and react to their overt exclusion while still in a social situation and when they believe to be observable by their excluders.

The present research compares smiling and emotion expression generally to other indicators of negative intraand interpersonal reactions as a result of ostracism, and in particular negative reactions towards the ostracizers. Based on the existing evidence, in Experiment 1 we test the hypothesis that ostracized participants will exhibit marked negative psychological reactions to their ostracism, including more negative attitudes toward their ostracizers. The main research question in Experiment 1 focuses on how both Duchenne and non-Duchenne smiling will be modulated by the experience of exclusion, and the second, related research question is how facial expressions of both positive and negative emotion relate to negative reactions to ostracism. ${ }^{28}$

In Experiment 2, our aim was to confirm and extend the findings of Experiment 1 by further exploring the function of smiling during exclusion. Smiling during distress can reflect self-presentation concerns, as well as adherence to display rules as to the appropriate expressions during a negative interaction, ${ }^{29}$ but it can also be part of an emotion regulation strategy, designed to downregulate the aversiveness of the ostracism, increase felt positive affect, and minimize negative affect. ${ }^{9}$ Therefore, 
in Experiment 2 we coded facial expressions of emotion in addition to assessing self-reported emotion immediately after the experimental period. This approach allowed us to assess whether smiling during an aversive period of exclusion is related to subsequent subjective levels of positive emotion. Additionally, Experiment 2 featured a group of external judges that thin-slice coded the visual behavior of ostracized participants on a number of affective dimensions. ${ }^{30}$ These were then compared for convergent validity to both expressive behavior during the interaction and the ostracized participants' levels of selfreported emotion. Experiment 2 also tested the robustness of the initial findings by filming a different set of confederates. Further, given that in both O-Cam and Cyberball participants always seemingly interact with students from another university, there remained the untested possibility of confounds due to outgroup effects. We tested this possibility by randomly assigning some participants to be to excluded by a salient outgroup of confederates of Indian ethnicity. The ingroup vs outgroup manipulation had no main or interaction effects on feelings of being excluded (manipulation check), primary needs, or negative and antisocial revenge attitudes. We conclude that exclusion findings using O-Cam and similar paradigms are unlikely to be affected by participants' perceptions of being excluded by an outgroup, and limit the findings to the main effects of exclusion experience.

\section{Methods}

We conducted two experiments: Experiment 1 was designed to examine how ostracism affects emotion expression in a social setting, and Experiment 2 was designed to replicate the results of Experiment 1 with a particular focus on smiling, and with self-reported emotion at the end of the exclusion period. This study applied the same procedure of O-Cam to both experiments but with the different participants and measures.

\section{O-Cam procedure}

O-Cam ${ }^{31}$ extends existing ostracism paradigms, where participants engage in an online ball-tossing game with two students from another university, into a more interpersonal and yet experimentally controlled experience of ostracism.

Although the paradigm has the appearance of a real webbased interaction, the other students are actually actors whose actions have been pretaped. Confederates give their accounts sequentially such that in all conditions, the two confederates speak for approximately $90 \mathrm{~s}$ each, and the participant gives

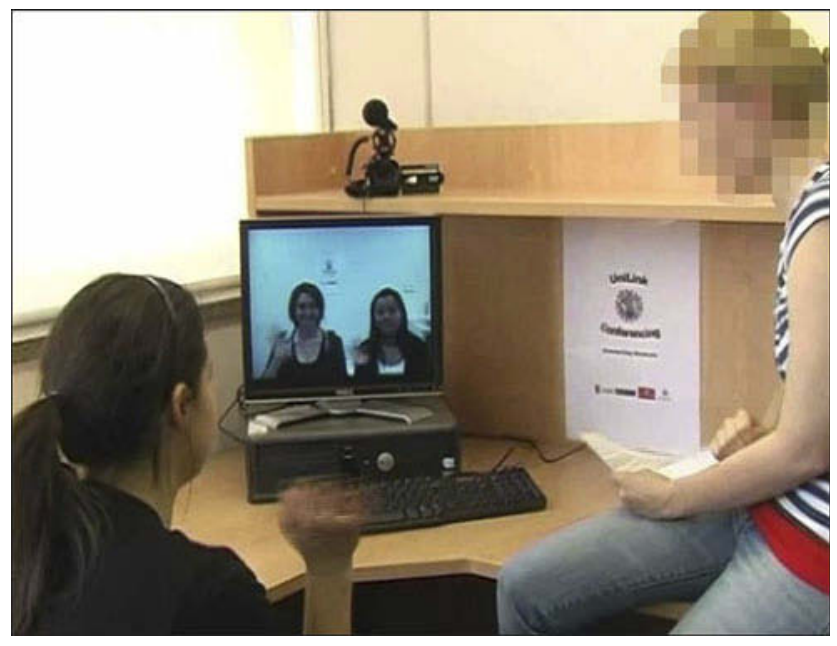

Figure I The experimenter (right) introducing the participant (left) to two female students (prerecorded confederates) at the beginning of the experimental interaction.

his or her account last. Participants in the inclusion condition are "attended to" by the confederates (ie, the confederates smile and appear to look at the participant) for the duration of their speech. In contrast, participants in the ostracism condition are "attended to" for approximately $15 \mathrm{~s}$, at which point the confederates begin to speak to each other and completely ignore the participant for the remainder of their talk time, approximately $75 \mathrm{~s}$ (see Figure 1 for a depiction of the O-Cam set up).

\section{Ethics statement}

All stages of this research were carried out in accordance with the Declaration of Helsinki concerning the protection of human subjects and the ethical conduct of human subjects research. All research participants provided their written-informed consent to participate in the research, and for their data to be used in the reporting of the results. This research was approved by the University of Sydney Human Research Ethics Committee.

\section{Experiment procedure}

Participants were informed that they would be trialing a new web-conference program called UniLink Conferencing with two students from a local university. The experimenter explained that in this conference, each student would give a short, prepared speech about his/her choice of degree, field of study, and subsequent career path.

After consenting to take part in the study and to have their session video-recorded via webcam, participants received a series of questions to assist them in preparing 
their speech (eg, "what subjects are you taking?"). They then practiced their speech with the experimenter both to reduce their nervousness and to ensure that participants in the inclusion condition would talk for the full duration of the O-Cam film, approximately $1 \mathrm{~min}$ and $30 \mathrm{~s}$.

Once the participant's speech was prepared, the experimenter started the appropriate conference tape and then left the laboratory, allowing the participant to continue the web-conference alone. Conference discussion time lasted for approximately 6 mins. When the conference connection was terminated, participants completed the post experimental measures, which included a manipulation check, followed by negative attitudes toward ostracism sources in Experiment 1, and self-experienced emotion in Experiment 2. Participants were then fully debriefed and thanked for their involvement.

\section{Participants}

\section{Experiment I}

Fifty-five first-year psychology students (45\% male; $M_{\text {age }}$ $=20.07, \mathrm{SD}=3.39$ ) at a large Australian university participated in return for course credit and were randomly assigned by a computer to be either ostracized or included by two same-sex individuals.

\section{Experiment 2}

Eighty-eight introductory psychology students (33\% male, $M_{\text {age }}=21.83, \mathrm{SD}=6.16$ ) participated in the study in exchange for course credit. As in Experiment 1, participants were randomly assigned to the ostracism or inclusion condition.

\section{Measurement \\ Experiment I}

Negative attitudes: A 24-item self-report questionnaire based on the categories proposed by Yoshimura, ${ }^{32}$ assessed participants' negative attitudes towards the ostracism sources. To increase the believability of the paradigm, participants answered each item for both confederates, and the average score was used. All items were assessed on a 5-point Likert scale (in which $1=$ strongly agree and $5=$ strongly disagree) and were scored such that higher scores signified higher levels of retaliation. These items were then averaged to give an overall retaliatory attitude score (overall scale $M=2.52, \mathrm{SD}=0.52$, Chronbach's $\alpha=0.95$ ). The questionnaire consisted of three sub-dimensions: active distancing, reputation defamation, and direct aggressiveness.
Active distancing refers to withdrawal of one's availability to another - essentially, the desire to ostracize the other students. Participants were asked two questions: "I would be willing to take part in another discussion with the two students from today's conference" (reverse-coded) and "I would be willing to participate in another discussion, but only if it were with a different group of students". A mean score is calculated by taking the average of the two items, $M=2.47, \mathrm{SD}=0.85$, $\alpha=0.68$.

For the measurement of reputation defamation, 16 items measured the extent to which participant attempted to reduce the positive public image of the students in the O-Cam conference by presenting them in a negative light to the experimenter. Participants were asked to rate four positive (eg, friendly, attractive; reverse-coded) and four negative (eg, ugly, cold) adjectives as accurate descriptions of the other students. Participants were also asked to rate whether they believed the other students would be likely to engage in eight activities - four positive (eg, do volunteer community work; reverse-coded) and four negative (eg, lie, steal), $M=2.59$, $\mathrm{SD}=0.56, \alpha=0.95$.

For the measurement of direct aggressiveness, six items assessed attempts to cause physical discomfort, emotional distress, or pain. Participants were asked to rate the extent to which they wished to nominate the students (confederates) from the conference to participate in six experiments which involved exposure to three positive experiences (eg, an experiment looking at increasing selfesteem through positive feedback) and three negative experiences (eg, an experiment looking at sleep deprivation or whether unavoidable electric shocks affects their fear response). Positive experience items were reverse scored such that greater values indicate more direct aggressiveness, $M=2.33, \mathrm{SD}=0.67, \alpha=0.88$.

Facial expression coding: Of the sample, 46 participants' webcam recordings (23 included and 23 ostracized) were selected for coding. Some video footage was not available or selected due to technical error and unavoidable issues (eg, participants leaning so far to one side that less than $50 \%$ of their face was within the frame of the webcam). The pattern of results as to the dependent variables (feelings of exclusion and negative and antisocial attitudes) was the same regardless of whether the full or coded sample subset was used. Videos were coded using the Emotion Facial Action Coding System (EMFACS), ${ }^{33}$ an abbreviated system of facial coding based on the comprehensive Facial Action Coding System (FACS), ${ }^{34}$ that only deals with facial action units involved in the production of discrete emotion. 
A coder notes expression events using a set of 33 action units empirically shown to be associated with the set of seven universal emotion expressions. ${ }^{35}$ Both in FACS and EMFACS, the focus is on describing the anatomical movement observed in the face, without interpreting the actual emotion. The facial behavior was coded by two FACS-certified coders. A sample of the videos $(10 \%)$ was coded by both and inter-coder reliability for the action units was calculated by doubling the number of action units on which the two coders agreed and calculating this number as a proportion of the total number of action units coded by both coders, with a mean agreement of 0.72 .

In order to obtain emotion judgments, the EMFACS codes were compared against a software-based emotion dictionary, ${ }^{36}$ which categorizes action unit combinations on the likelihood that they reflect a particular emotion. For the purposes of the study, the focus was on smiling (as measured by both Duchenne and non-Duchenne smiling), but we also examined relevant negative emotion expressions to ostracism: namely anger and sadness.

\section{Experiment 2}

Self-reported emotion: Participants completed an 8-item emotion inventory on a 5-point Likert scale (eg, While I was watching the web conference I felt: relaxed, tense, angry, happy, sad, energetic, lively, active) where $1=$ not at all and $5=$ very much.

Facial expression coding: Facial expressions were coded using the same FACS-certified coders and procedure as Experiment 1. We compared ostracized participants who were in the coded subsample vs those who were not, as well as included participants in each subsample, and confirmed that there were no differences in feelings of inclusion, primary need threat, or negative and antisocial attitudes, all $P$-values $>0.2$.

Thin-slice coding: Video recordings of the ostracized participants $(n=26)$ were coded by a group of 21 undergraduate students who served as judges and were not acquainted with the participants or the experimental design. The responses of three judges were excluded because they self-reported an autistic-spectrum diagnosis. The final judge sample was therefore of 18 judges ( 6 males and 12 females). The final $30 \mathrm{~s}$ of each recorded ostracism experimental period (the experimenter ended the interaction after $1 \mathrm{~min}$ 30 s) was edited and converted to sound-less film clip.

After watching each video clip, judges rated the participant on several characteristics and then made a set of judgments, based on the categories by Mason et al. ${ }^{37}$ Using a $0-10$ slider scale, with 1 -point increments, where $0=$ none/not at all, and $10=$ extremely/the most possible, judges rated the individual in each clip on the following statements: How well is this person coping with being excluded?; How well is this person able to control his or her emotions?; How much stress is this person experiencing?; How much is this person experiencing angry thoughts about being excluded?; How much amusement is this person experiencing during this time?; and How much sadness is this person experiencing?. The statements were presented in random order for each video, and the presentation order of the clips was counterbalanced. The average measure of intraclass correlation (18 raters, 156 items) was 0.90 .

\section{Results \\ Experiment I \\ Manipulation check}

A manipulation check determined the effectiveness of the O-Cam ostracism manipulation. Ostracized participants reported feeling significantly more ignored $(M=3.21$, $\mathrm{SD}=1.29)$ as compared to included participants $(M=2.26$, $\mathrm{SD}=0.98 ; t[53]=-3.08, P<0.05)$, confirming the success of the experimentally induced ostracism experience.

\section{Negative attitudes}

ANOVA examined the effect of being ostracized on active distancing, reputation defamation and direct aggressiveness separately, as well as the overall negative attitude score. Being ostracized was associated with more negative attitudes towards ostracism sources, $F(1,53)=13.47, P=0.001$, $\eta_{p}{ }^{2}=0.20$; specifically, significantly greater active distancing $F(1,53)=10.19, P=0.002, \eta_{p}{ }^{2}=0.16$; and reputation defamation, $F(1,53)=15.65, P<0.001, \eta_{p}{ }^{2}=0.23$, though not direct aggression (Table 2).

\section{Emotion expression}

We used a multivariate ANOVA that compared ostracized and included participants on each of the emotion expression frequencies during the experimental interaction. Given that the paradigm experimentally controls the time in each condition, we retained our main dependent variable as frequency of expression. The overall model was not significant $F(3,42)=2.42, P=0.097$ (see also Table 2).

When looking at the emotion expression variables individually, ostracized participants exhibited equivalent frequency of smiling during the experimental phase (there was in fact a statistically nonsignificant tendency for ostracized individual to display more smiles during the 
Table I Age and gender distribution of included vs ostracized participants

\begin{tabular}{|l|l|l|l|l|}
\hline Experiment & Variables & Included & Ostracized & Significant difference \\
\hline Experiment I & $\begin{array}{l}\text { Age (M) } \\
\text { Gender }\end{array}$ & $\begin{array}{l}20.26 \\
\text { Male }=12 \\
\text { Female }=15\end{array}$ & $\begin{array}{l}19.89 \\
\text { Male }=13 \\
\text { Female }=15\end{array}$ & $\begin{array}{l}t_{53}<1 ; P>0.6 \\
\chi^{2}=0.02, P>0.8\end{array}$ \\
\hline Experiment 2 & $\begin{array}{l}\text { Age (M) } \\
\text { Gender }\end{array}$ & $\begin{array}{l}22.03 \\
\text { Male }=13 \\
\text { Female }=29\end{array}$ & $\begin{array}{l}21.03 \\
\text { Male }=16 \\
\text { Female }=30\end{array}$ & $\begin{array}{l}t_{68}<1 ; P>0.5 \\
\chi^{2}=0.15, P>0.8\end{array}$ \\
\hline
\end{tabular}

experimental phase, $P=0.09$ ). Similarly, aside from a nonsignificant tendency for ostracized participants to display slightly more anger expressions $(P=0.09)$, there was no evidence that ostracized individuals displayed more negative expressions of emotion during the experimental interaction. Ostracized participants' facial expressions, therefore, were not generally more negative than their included counterparts. Therefore, there was no evidence that facial expressions during ostracism relate to the negative attitudes that participants form toward the sources of their ostracism.

A caveat of the above findings is that both anger and sadness expressions showed typically very low frequencies. This result has two implications. Firstly, it compromises the validity of statistical analyses through the restriction of variance. At a theoretical level, however, it highlights the strong display rules that govern interactions with strangers, even when those interactions are aversive.

\section{Experiment 2}

Manipulation check

As in Experiment 1, ostracized participants felt significantly less "included" $(M=.54, \mathrm{SD}=0.72)$ than included participants $(M=2.83, \quad \mathrm{SD}=0.96, \quad t[86]=6.82, \quad P<0.001)$ (Table 3).

\section{Self-reported emotion}

Ostracized participants reported significantly lower levels of happiness, $F(1,85)=2.16, P=0.03, \eta p^{2}=0.05$ subsequent to the experimental period, as well as significantly higher

Table 2 Experiment I included vs ostracized participants on negative attitudes and emotion expressions during the interaction

\begin{tabular}{|c|c|c|c|c|c|}
\hline \multirow[t]{2}{*}{ Variables } & \multirow{2}{*}{$\begin{array}{l}\text { Included }(n=27) \\
M(S D)\end{array}$} & \multirow{2}{*}{$\begin{array}{l}\text { Ostracized }(n=28) \\
M(S D)\end{array}$} & \multirow[t]{2}{*}{$P$-value } & \multicolumn{2}{|c|}{$95 \% \mathrm{Cl} \Delta$} \\
\hline & & & & LL & UL \\
\hline Manipulation check (“I felt included”) & $2.26(1.01)$ & $3.39(1.27)$ & 0.003 & 0.33 & 1.58 \\
\hline \multicolumn{6}{|l|}{ Negative attitudes toward ostracism sources } \\
\hline Active distancing & $2.13(0.63)$ & $2.80(0.91)$ & 0.002 & 0.25 & 1.10 \\
\hline Reputation defamation & $2.32(0.23)$ & $2.85(0.66)$ & $<0.001$ & 0.26 & 0.80 \\
\hline Physical aggressiveness & $2.20(0.52)$ & $2.46(0.78)$ & 0.16 & -0.10 & 0.62 \\
\hline \multirow[t]{3}{*}{ Overall } & $2.28(0.27)$ & $2.75(0.60)$ & 0.001 & 0.21 & 0.72 \\
\hline & Included $(n=23)$ & Ostracized $(n=23)$ & \multirow[t]{2}{*}{$P$-value } & \multicolumn{2}{|c|}{$95 \% \mathrm{Cl} \Delta$} \\
\hline & $M(\mathrm{SD})$ & $M(\mathrm{SD})$ & & $L L$ & $U L$ \\
\hline \multicolumn{6}{|l|}{ Emotion expression } \\
\hline Anger & $0.26(0.54)$ & $0.70(1.06)$ & 0.09 & -0.07 & 0.94 \\
\hline Sadness & $0.00(-)$ & $0.17(0.58)$ & 0.16 & -0.07 & 0.42 \\
\hline Happiness & $4.91(2.83)$ & $6.87(4.53)$ & 0.09 & -0.29 & 4.20 \\
\hline Duchenne smile & $2.88(2.77)$ & $3.52(2.97)$ & 0.45 & -1.07 & 2.35 \\
\hline Non-Duchenne smile & $1.91(2.59)$ & $3.00(2.28)$ & 0.14 & -0.36 & 2.54 \\
\hline
\end{tabular}

Notes: $\mathrm{N}=55$, except for emotion expression where $\mathrm{N}=46$. The pattern of results for the manipulation check and retaliatory attitudes are the same regardless of whether the full sample is analyzed or the subset for which emotion expressions were coded. 
Table 3 Experiment 2 included vs ostracized participants on self-reported emotion and emotion expressions during the interaction

\begin{tabular}{|c|c|c|c|c|c|}
\hline \multirow[t]{2}{*}{ Variables } & \multirow{2}{*}{$\begin{array}{l}\text { Included }(n=42) \\
M(S D)\end{array}$} & \multirow{2}{*}{$\begin{array}{l}\text { Ostracized }(n=46) \\
M(\mathrm{SD})\end{array}$} & \multirow[t]{2}{*}{$P$-value } & \multicolumn{2}{|c|}{$95 \% \mathrm{Cl} \Delta$} \\
\hline & & & & $L L$ & UL \\
\hline Manipulation check (“I felt included”) & $2.83(0.96)$ & $1.59(0.75)$ & $<0.001$ & -1.61 & -0.88 \\
\hline \multicolumn{6}{|l|}{ Self-reported emotion } \\
\hline “Angry" & $1.10(0.37)$ & $1.96(1.11)$ & $<0.001$ & 0.50 & 1.22 \\
\hline "Sad" & $1.29(0.60)$ & $2.09(1.06)$ & $<0.001$ & 0.43 & 1.17 \\
\hline \multirow[t]{3}{*}{ “Happy” } & $3.17(0.79)$ & $2.78(0.88)$ & 0.03 & -0.75 & -0.03 \\
\hline & Included $(n=19)$ & Ostracized $(n=26)$ & \multirow[t]{2}{*}{$P$-value } & \multicolumn{2}{|c|}{$95 \% \mathrm{Cl} \Delta$} \\
\hline & $M(\mathrm{SD})$ & $M(\mathrm{SD})$ & & $L L$ & $U L$ \\
\hline \multicolumn{6}{|l|}{ Emotion expression } \\
\hline Anger & $0.58(0.90)$ & $0.62(1.02)$ & 0.90 & -0.56 & 0.63 \\
\hline Sadness & $0.95(\mathrm{I} .5 \mathrm{I})$ & $0.15(0.46)$ & 0.02 & -1.43 & -0.16 \\
\hline Overall smiling & $6.95(4.97)$ & $6.81(4.42)$ & 0.92 & -2.98 & 2.70 \\
\hline Duchenne & $4.79(4.57)$ & $4.46(4.00)$ & 0.80 & -2.91 & 2.26 \\
\hline Non-Duchenne & $1.32(1.11)$ & 1.73 (1.64) & 0.35 & -0.46 & 1.29 \\
\hline
\end{tabular}

Notes: $\mathrm{N}=88$, except for emotion expression where $\mathrm{N}=45$. The patterns of results for the manipulation check are the same regardless of whether the full sample is analyzed or the subset for which emotion expressions were coded.

levels of anger, $F(1,85)=22.96, P<0.001, \eta_{p}{ }^{2}=0.21$, and sadness, $F(1,85)=-4.31, P<0.001, \eta_{p}{ }^{2}=0.18$, compared to included participants (Table 2).

Subsequent analyses focused on the experience of ostracized participants, and the relationships between levels of smiling, both Duchenne and non-Duchenne, during the experimental period, and self-reported happiness at the conclusion of the experimental interaction. The frequency of Duchenne smiling during exclusion was positively related to postexclusion self-reported happiness, $r=0.45, P=0.023, \mathrm{n}=26,95 \% \mathrm{CI}(0.08,0.71)$. The relationship between non-Duchenne smiling and postexclusion self-reported happiness, on the other hand, was both negative and nonsignificant, $r=-0.21, P=0.298,95 \%$ CI $(-0.55$, $0.19)$. These findings support existing research on the positive intrapersonal functions of Duchenne smiling specifically. ${ }^{8}$ There were no other relations observed between self-reported postostracism affect and expressed affect.

\section{Emotion expression}

A multivariate ANOVA tested the effect of being ostracized on the frequency of smiling (Duchenne and non-Duchenne) , anger, and sadness. The overall multivariate model was again, not significant, $F(4,40)=1.86, P=0.14$. Ostracized participants, therefore, exhibited levels of smiling, both Duchenne and non-Duchenne, that were statistically equivalent to their included counterparts (see Figure 2 for a comparison of the proportion of Duchenne vs nonDuchenne smiling in both Experiment 1 and Experiment 2).

In Experiment 2, there was no evidence of greater frequencies of negative emotion expressions, and though there was a significant univariate difference in sadness expression, ostracized participants actually expressed less sadness than included participants, $F(1,43)=2.53$, $P=0.015, \eta p^{2}=0.13$ (see Table 4 for a complete report of all the coded emotion frequencies for both Experiment 1 and Experiment 2).

\section{Thin slice coding}

Thin slice coding was performed on ostracized participants only, in order to examine whether the relation of the thin slice coded categories with both emotion expression during ostracism, and self-reported emotion postostracism. In general, individuals who expressed more EMFACS-coded sadness and anger during ostracism were also judged as coping less well with their exclusion; sadness $r=-0.41, P=0.039,95 \% \mathrm{CI}$ $(-0.69,-0.02)$, anger $r=-0.42, P=0.032,95 \%$ CI: $(-0.70$, $-0.04)(\mathrm{n}=26$ for all the correlations reported). Individuals who expressed more anger were judged as less able to control their emotions; $r=-0.40, P=0.041,95 \%$ CI $(-0.68,-0.02)$, and individuals who expressed more sadness were also judged as experiencing more sadness $r=0.41, P=0.03695 \%$ CI $(0.03,0.69)$. Interestingly, ostracized participants who expressed more Duchenne smiling were also judged as experiencing more amusement, $r=0.60, P=0.001,95 \% \mathrm{CI}$ 

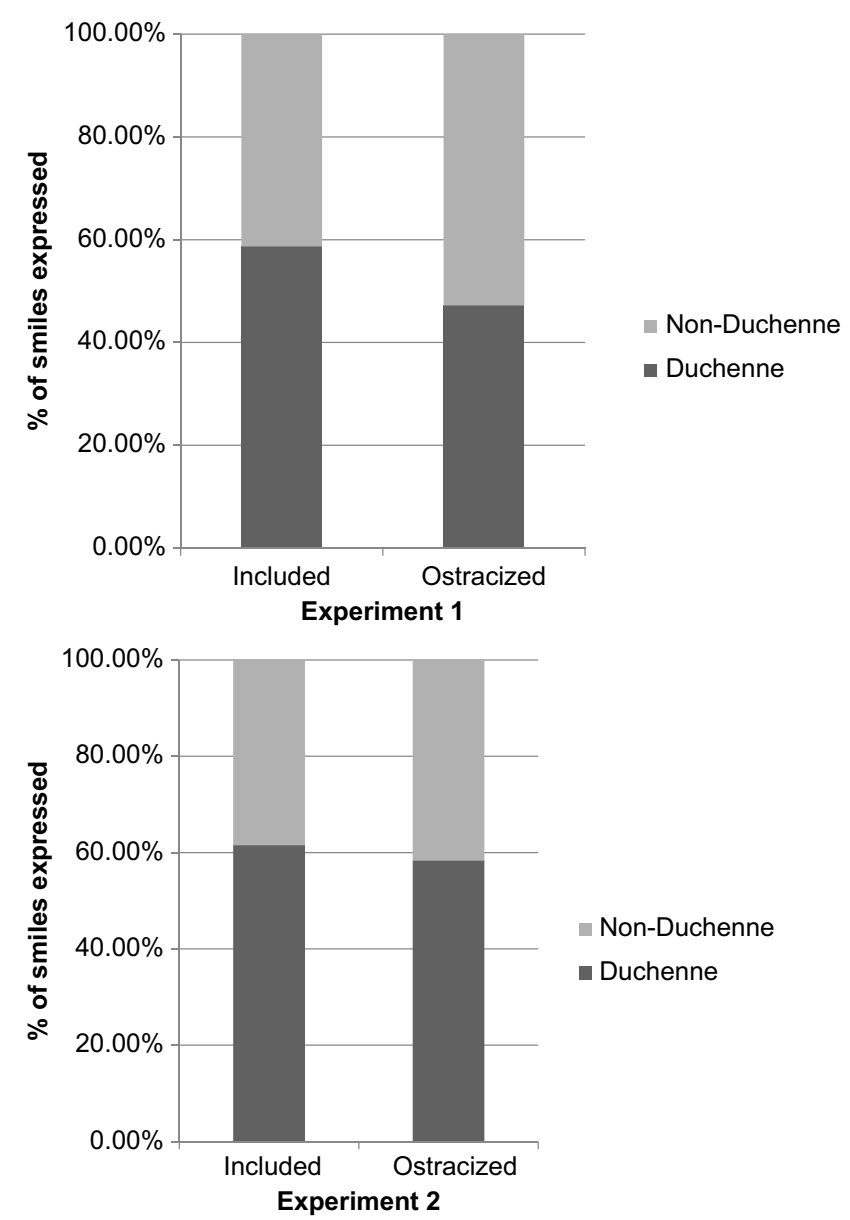

Figure 2 A comparison of the proportion of Duchenne vs non-Duchenne smile expressions during the experimental interaction for included vs ostracized participants for both Experiment $I$ and Experiment 2.

$(0.28,0.80)$, but the same relation did not hold for nonDuchenne smiling $r=-0.01, P>0.96$. These results indicate significant congruence between the expressive behavior as coded both objectively and using thin-slice impression coding.

The relationship between the observer-coded category of "amusement" and participant self-reported happiness was $r=0.34, P=0.093$. While non-significant, this correlation was not significantly different to that obtained between Duchenne smiling and self-reported happiness, $z=-0.46, P=0.647$, using Fisher's $r$ to $z$ transformation.

Experiment 2 showed evidence of a self-regulation and display management function of smiling during ostracism in that participants who exhibited more Duchenne smiling during their exclusion also reported higher levels of positive emotion after the ostracism, and were also rated by a group of judges as experiencing more amusement at their exclusion.

\section{Discussion}

The present set of experiments adds to the existing evidence of positive emotion displays during negative and aversive interpersonal experiences. ${ }^{9,38}$ Not only did excluded participants smile just as much (if not slightly more) than their included counterparts, they also exhibited comparable levels of Duchenne smiling. Moreover, the analyses suggest little to no expression of negative emotion by excluded participants, despite the fact they report negative reactions to being excluded, including negative attitudes towards the sources of their exclusion. In Experiment 2, we were also able to confirm that ostracized participants smile and manage their facial display despite the fact they report experiencing significantly higher levels of negative affect. In sum, facial expressions of emotion in

Table 4 Experiment I and Experiment 2 means across all codable emotion expression types

\begin{tabular}{|c|c|c|c|c|c|}
\hline \multirow[t]{2}{*}{$\begin{array}{l}\text { Emotion expression (as proportion of codable } \\
\text { expressions) }\end{array}$} & \multicolumn{2}{|c|}{$\begin{array}{l}\text { Experiment I Mean } \\
(n=46)\end{array}$} & \multicolumn{2}{|c|}{$\begin{array}{l}\text { Experiment } 2 \text { Mean } \\
(n=45)\end{array}$} & \multirow[t]{2}{*}{$\begin{array}{l}\text { Significant } \\
\text { difference }^{a}\end{array}$} \\
\hline & Included & Ostracized & Included & Ostracized & \\
\hline Anger & 0.0213 & 0.0470 & 0.0391 & 0.0428 & \\
\hline Contempt & 0.0839 & 0.1009 & 0.1034 & 0.0487 & \\
\hline Disgust & 0.0570 & 0.0357 & 0.0885 & 0.0654 & \\
\hline Fear & 0.0683 & 0.0074 & 0.0897 & 0.0158 & $\mathrm{I}, 2$ \\
\hline Happiness & 0.6874 & 0.7074 & 0.5935 & 0.7440 & \\
\hline Duchenne (felt) happiness & 0.4313 & 0.3409 & 0.4144 & 0.4704 & \\
\hline Non-Duchenne (unfelt) happiness & 0.2561 & 0.3313 & 0.1276 & 0.2300 & \\
\hline Sadness & 0.0000 & 0.0204 & 0.0593 & 0.0208 & 2 \\
\hline Positive emotion overall & 0.6874 & 0.7074 & 0.5935 & 0.7440 & \\
\hline Negative emotion overall & 0.2326 & 0.2096 & 0.3800 & 0.1892 & 2 \\
\hline
\end{tabular}

Notes: Means represent frequency of each emotion expression frequency as a proportion of the number of codable expressions. Codable expressions reflect combinations of key facial actions that are associated with an emotion state coded as an "event" within EMFACS. ${ }^{33}$ andicates in which study (I and/or 2$)$ the means between included and ostracized participants were significantly different from each other at the $\alpha=0.05$ level. 
ostracized individuals do not betray their exclusion, or the negative attitudes they hold towards the sources of their ostracism.

The results of both experiments indicate that, despite being ignored for the duration of the interaction, ostracized participants continue to show facial expressivity. These results highlight the strong display rules that govern interactions with strangers, particularly when those interactions are negative and involve exclusion. This research establishes experimental evidence that mirrors the observations from interviews with real-world targets of ostracism who often state that they make attempts to hide their distress and behave normally, expressing their distress only when alone. ${ }^{39}$

The current research also found that facial expression in this context was not predictive of the negative reactions that ostracized participants exhibited towards the sources of their exclusion. While there is some evidence that facial expression can provide a guide to subsequent antisocial or cooperative behavior in children, ${ }^{40}$ regulatory control and display rule adherence in adults means that facial expression of emotion is not necessarily diagnostic of an individual's social experience or their subsequent behavior.

The findings of the present set of studies were obtained using a novel paradigm that is able to examine expressive behavior during a finite period of social exclusion. Our analysis of facial expression in the context of ostracism also offers a different and complementary perspective to the considerable research on the impacts of exclusion on cognition, emotion, and behavior. These studies demonstrate that ostracized participants manage their facial expressions of emotion to a level that is statistically indistinguishable from their included counterparts.

Although Duchenne smiling can occur in nonenjoyment situations, the results of these experiments provide support to the hypothesis that such displays, aside from conforming to display norms, can serve an emotion regulation function. The presence of Duchenne smiling in both studies optimistically suggests that ostracized individuals do spontaneously regulate their emotion experience during this time, which in Experiment 2 was also linked to higher levels of postexperimental self-reported happiness. If emotion regulation is comprised of the relatively maladaptive strategy of suppressing the emotion vs the adaptive strategy of reappraising a situation in order to feel a more positive emotion, ${ }^{41}$ individuals that expressed greater levels of Duchenne smiling may be reappraising the situation, finding amusement in the experience, and increasing the positive outcomes of an otherwise aversive experience.

\section{Limitations}

The findings of the present set of studies were obtained using a novel paradigm that is able to examine expressive behavior during a finite period of social exclusion. A limitation of this research is that the significant coding demands tend to limit the sample size of such studies. Thin-slice coding may provide a viable alternative, in addition to advancements in technological capacities, such as the automated coding of facial expressions, ${ }^{27}$ and other nonverbal indicators such as eye movements, all which will greatly enable future research to examine the multitude of information provided by individuals' nonverbal behavior during ostracism.

The present experimental paradigm also measures facial expressions during a limited time period, which may limit the variability and extent of emotion expression change. It may well be the case that facial expressions of emotion show markedly different patterns when measured in different settings, such as when an ostracized individual recalls the experience of being excluded, or across time, such as when an individual experiences chronic and repeated instances of exclusion (eg, a student who is repeatedly excluded in his or her school and classroom). In instances where individuals are more subtly excluded or where their exclusion is made less conspicuous, more negative expressions of emotion may emerge. ${ }^{27}$ Similarly, there is no research to date that examines how facial expressions might also be modulated by the presence of others, ie, the presence of ostracism "witnesses" in addition to the ostracism sources, a situation where the desire to manage one's reactions may be even stronger, and yet the ability to do so more difficult.

\section{Conclusion and future research}

Given that ostracism is an aversive experience that individuals must often "suffer through" in social settings, the O-Cam paradigm provides an ecologically valid method to study the management of expressive behavior during aversive interpersonal experiences, adding to the existing evidence of facial display management during other types of distressing experience. ${ }^{8,38}$ Both experiments reported here show consistent evidence that ostracized individuals manage their facial expressions of emotion through what they report to be a highly negative and unpleasant experience, through the use of significant levels of smiling, and minimal expression of negative emotion.

To the extent that self-regulation is a finite intrapersonal resource, $^{42}$ facial display management in the context of 
ostracism, such as suppressing or masking negative emotion, may deplete self-regulatory capacity. ${ }^{43}$ Future research will be able to investigate this possibility, and examine selfregulation failures that are the result of facial display management, such as self-defeating behavior, and less regulated behavior in other tasks or domains (such as resisting unhealthy food or reduced perseverance in a task). ${ }^{17}$

Our experiments also show that certain individuals are able to up-regulate positive affect during an aversive experience, which could be observed both in their expressive behavior and their emotion self-reports. Future research will benefit from directly inquiring with targets of ostracism as to their emotion regulation strategies, which will, in turn, inform any attempt to build resilience to ostracism in vulnerable populations such as children and adolescents. The key to understanding how we can reduce and prevent the negative effects of ostracism in young adults may very well lie in identifying the cognitive and regulatory strategies that these ostracized participants used, and how these strategies may be trained, developed and implemented more broadly.

\section{Acknowledgment}

Funded by an ARC Discovery Project Grant DP0666929 to L Zadro (co-investigator M Moulds) as well as Dong-A University Research Fund awarded to D Kim.

\section{Disclosure}

Dr Lisa Zadro reports grants from Australian Research Council during the conduct of the study. The other authors report no conflicts of interest in this work.

\section{References}

1. Frijda NH. The Emotions. New York (NY): Cambridge University Press; 1986.

2. Scherer KR. On the nature and function of emotion: a component process approach. In: Scherer KR, Ekman P, editors. Approaches to Emotion. Hillsdale (NJ): Erlbaum; 1984:293-317.

3. Matsumoto D, Keltner D, Shiota MN, O'Sullivan M, Frank MG. Facial expression of emotion. In: Lewis M, Haviland-Jones JM, Feldman Barrett L, editors. Handbook of Emotions. 3rd ed. New York: Guildford Press; 2008:211-234.

4. Goffman E. The Presentation of Self in Everyday Life. Oxford (England): Doubleday; 1959.

5. Ekman P, Friesen WV. Unmasking the Face. Englewood Cliffs (NJ): Prentice Hall; 1975.

6. Keltner D. Evidence for the distinctness of embarrassment, shame, and guilt: a study of recalled antecedents and facial expressions of emotion. Cogn Emot. 1995;10(2):155-172. doi:10.1080/026999396380312

7. Matsumoto D. Cultural influences on facial expressions of emotion. South Commun J. 1991;56(2):128-137. doi:10.1080/10417949109372824
8. Papa A, Bonnano GA. Smiling in the face of adversity: the interpersonal and intrapersonal functions of smiling. Emotion. 2008;8 (1):1-12. doi:10.1037/1528-3542.8.1.1

9. Ansfield ME. Smiling when distressed: when a smile is a frown turned upside down. Pers Soc Psychol Bull. 2007;33(6):763-775. doi: $10.1177 / 0146167206297398$

10. Kraft TL, Pressman SD. Grin and bear it the influence of manipulated facial expression on the stress response. Psychol Sci. 2012;23 (11):1372-1378. doi:10.1177/0956797612445312

11. Frank MG, Ekman P, Friesen WV. Behavioral markers and recognizability of the smile of enjoyment. J Pers Soc Psychol. 1993;64 (1):83-93. doi:10.1037/0022-3514.64.1.83

12. Ambadar Z, Cohn JF, Reed LI. All smiles are not created equal: morphology and timing of smiles perceived as amused, polite, and embarrassed/nervous. $J$ Nonverbal Behav. 2009;33(1):17-34. doi:10.1007/s10919-008-0059-5

13. Krumhuber EG, Manstead ASR. Can Duchenne smiles be feigned? New evidence on felt and false smiles. Emotion. 2009;9(6):807-820. doi:10.1037/a0017844

14. Gunnery SD, Reuben MA. Perceptions of Duchenne and nonDuchenne smiles: a meta-analysis. Cogn Emot. 2016;30 (3):501-515. doi:10.1080/02699931.2015.1018817

15. Lustgraaf CJN, Sacco DF, Young SG. Smiling and social perception: evolutionary, neuroscientific, and social cognitive considerations. In: Freitas-Magalhães A, editor. Emotional Expression: The Brain and the Face. Vol. 6. Porto (Portugal): University Fernando Pessoa Press; 2015:115-147.

16. Williams KD, Cheung KT, Choi W. Cyberostracism: effects of being ignored over the internet. J Pers Soc Psychol. 2000;79(5):748-762. doi:10.1037/0022-3514.79.5.748

17. Baumeister RF, DeWall CN, Ciarocco NJ, Twenge JM. Social exclusion impairs self-regulation. $J$ Pers Soc Psychol. 2005;88 (4):589-604. doi:10.1037/0022-3514.88.3.421

18. Williams KD. The Power of Silence. New York (NY): Guilford Press; 2001.

19. Blackhart GC, Eckel LA, Tice DM. Salivary cortisol in response to acute social rejection and acceptance by peers. Biol Psychol. 2007;75 (3):267-276. doi:10.1016/j.biopsycho.2007.03.005

20. Eisenberger NA, Leiberman MD, Williams KD. Does rejection hurt? An fMRI study of social exclusion. Science. 2003;302 (5643):290-292. doi:10.1126/science.1089134

21. Gerber J, Wheeler L. On being rejected: a meta-analysis of experimental research on rejection. Perspect Psychol Sci. 2009;4 (5):468-488. doi:10.1111/j.1745-6924.2009.01158.x

22. Smart Richman L, Leary MR. Reactions to discrimination, stigmatization, ostracism, and other forms of interpersonal rejection: a multimotive model. Psychol Rev. 2009;116(2):365-383. doi:10.1037/a0015250

23. Leary MR, Koch EJ, Hechenbleikner NR. Emotional responses to interpersonal rejection. In: Leary MR, editor. Interpersonal Rejection. New York: Oxford University Press; 2001:145-166.

24. Zadro L. Silent rage: when being excluded and ignored leads to acts of aggression, vengeance, and/or self-harm. In: Forgas JP, Kruglanski A, Williams KD, editors. Social Conflict and Aggression. New York (NY): Psychology Press; 2011:201-216.

25. Staebler K, Renneberg B, Stopsack M, Fiedler P, Weiler M, Roepke S. Facial emotional expression in reaction to social exclusion in borderline personality disorder. Psychol Med. 2011;41 (9):1929-1938. doi:10.1017/S0033291711000080

26. Kawamoto T, Nittono H, Ura M. Cognitive, affective, and motivational changes during ostracism: an ERP, EMG, and EEG study using a computerized cyberball task. Neurosci J. 2013;304674. doi:10.1155/2013/304674

27. Schaafsma SM, Pfaff DW, Spunt RP, Adolphs R. Deconstructing and reconstructing theory of mind. Trends Cogn Sci. 2015;19(2):65-72. doi:10.1016/j.tics.2014.11.007 
28. Chow RM, Tiedens LZ, Govan C. Excluded emotions: the role of anger in antisocial responses to ostracism. J Exp Soc Psychol. 2008;44(3):896-903. doi:10.1016/j.jesp.2007.09.004

29. Ekman P, Friesen WV. Detecting deception from body or face. J Pers Soc Psychol. 1974;29(3):288-298. doi:10.1037/h0036006

30. Murphy N. Using thin slices for behavioral coding. $J$ Nonverbal Behav. 2005;29:235-246. doi:10.1007/s10919-005-7722-x

31. Goodacre R, Zadro L. O-Cam: a new paradigm for investigating the effects of ostracism. Behav Res Methods. 2010;42(3):768-774. doi:10.3758/BRM.42.3.768

32. Yoshimura S. Goals and emotional outcomes of revenge activities in interpersonal relationships. J Soc Pers Relat. 2007;24(1):87-98. doi:10.1177/0265407507072592

33. Ekman P, Irwin W, Rosenberg E. Emotional Facial Action Coding System (EMFACS-8) [Unpublished manuscript]. San Diego (CA): University of California at San Diego; 1994.

34. Ekman P, Friesen WV. The Facial Action Coding System (FACS). A Technique for the Measurement of Facial Action. Palo Alto (CA): Consulting Psychologists Press; 1978.

35. Ekman P, Matsumoto D, Friesen W. Facial expression in affective disorders. In: Ekman P, Rosenberg E, editors. What the Face Reveals. Basic and Applied Studies of Spontaneous Expression Using the Facial Action Coding System (FACS). New York: Oxford University Press; 2005:429-440.
36. Levenson RW FACS/EMFACS emotion predictions [Unpublished computer program]. Berkeley: University of California; 2005.

37. Mason AE, Sbarra DA, Mehl MR. Thin-slicing divorce: thirty seconds of information predict changes in psychological adjustment over 90 days. Psychological Science. 2010;21:1420-1422. doi:10.1177/ 0956797610381507

38. Keltner D, Bonanno GA. A study of laughter and dissociation: distinct correlates of laughter and smiling during bereavement. J Pers Soc Psycho. 1997;73(4):687-702. doi:10.1037/0022-3514.73.4.687

39. Zadro L Ostracism: Empirical studies inspired by real-world experiences of silence and exclusion [dissertation]. Sydney (Australia): University of New South Wales; 2004.

40. Matsumoto D, Haan N, Gary Y, Theodorou P, Cooke-Carney C. Preschoolers' moral actions and emotions in Prisoner's Dilemma. Dev Sci. 1986;22(5):663-670.

41. Gross JJ, John OP. Individual differences in two emotion regulation processes: implications for affect, relationships, and well-being. $J$ Pers Soc Psychol. 2003;85(2):348-362. doi:10.1037/0022-3514.85.2.348

42. Muraven M, Baumeister RF. Self-regulation and depletion of limited resources: does self-control resemble a muscle? Psychol Bull. 2000;126(2):247-259. doi:10.1037/0033-2909.126.2.247

43. Richards JM, Gross JJ. Composure at any cost? The cognitive consequences of emotion suppression. Pers Soc Psychol Bull. 1999;25 (8):1033-1044. doi:10.1177/01461672992511010
Psychology Research and Behavior Management

\section{Publish your work in this journal}

Psychology Research and Behavior Management is an international, peer-reviewed, open access journal focusing on the science of psychology and its application in behavior management to develop improved outcomes in the clinical, educational, sports and business arenas. Specific topics covered in the journal include: Neuroscience, memory and decision making; Behavior modification and management; Clinical

\section{Dovepress}

applications; Business and sports performance management; Social and developmental studies; Animal studies. The manuscript management system is completely online and includes a very quick and fair peer-review system, which is all easy to use. Visit http://www. dovepress.com/testimonials.php to read real quotes from published authors.

Submit your manuscript here: https://www.dovepress.com/psychology-research-and-behavior-management-journal 